\title{
Restrictive Versus Liberal Fluid Bolus Therapy in Pediatric Septic Shock: Should It Be Debated
}

\author{
Saptadi Yuliarto* \\ Department of Pediatrics, Indonesia
}

ISSN: 2576-9200

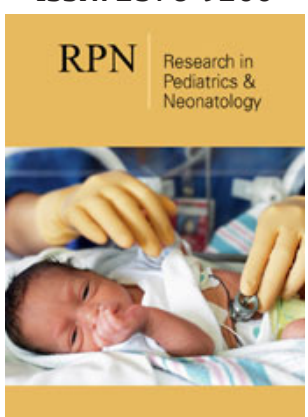

${ }^{* 1}$ Corresponding author: Saptadi Yuliarto, Consultant of Emergency and Intensive Care, Division of Pediatric Emergency and Intensive Care Department of Pediatrics, Medical Faculty, University of Brawijaya, Malang, Indonesia

Submission: 眥 August 13, 2019

Published: 啙August 19, 2019

Volume 3 - Issue 3

How to cite this article: Yuliarto $S$. Restrictive Versus Liberal Fluid Bolus Therapy in Pediatric Septic Shock: Should It Be Debated. Res Pediatr Neonatol. 3(3). RPN.000570.2019.

DOI: 10.31031/RPN.2019.03.000570

Copyright@ Saptadi Yuliarto, This article is distributed under the terms of the Creative Commons Attribution 4.0 International License, which permits unrestricted use and redistribution provided that the original author and source are credited.

\section{Opinion}

To date, sepsis has contributed significantly to the child mortality rate, which is around $8.9 \%$ in developed countries to $14.2 \%$ in developing countries [1-3]. The most common cause of death (23.1-34.6\%) was refractory shock [2-4], of which most occured in the first 3 days [5]. An additional hour of persistent shock was associated with $>2$-fold increased odds of mortality [6]. This shows that early treatment of septic shock is one of the keys to reduce sepsis mortality.

Fluid bolus is the main therapy for pediatric septic shock. International consensus recommends fluid bolus therapy (FBT) $10-60 \mathrm{~mL} / \mathrm{kg}$ in the first hour, accompanied by monitoring for hepatomegaly or increased work of breathing [7]. Resuscitation practice consistent with these guidelines can reduce mortality $[6,8,9]$. Current international guideline was based on some outstanding pioneer studies; unfortunately, all of them are retrospective observational and single-center studies, with a small sample size. Thus, it needs to be reevaluated whether the effectiveness of FBT in daily practice, certainly has a causal relationship with patient survival, or it was just a representation of lower severity illness in the survivor group.

FEAST (Fluid expansion as Supportive Therapy) trial, the first randomized control trial (RCT) study, with many subjects (3141 subjects) and multicenter in Africa, became the starting point for re-evaluation of FBT in recent years. In subjects with severe infections accompanied by impaired consciousness, respiration and perfusion, this study showed FBT of normal saline or $5 \%$ albumin given $20-40 \mathrm{~mL} / \mathrm{kg}$ in 1 hour increased mortality compared to maintenance fluid administration ( $R R=1.45,95 \% \mathrm{CI}, 1.13-1.86$; $\mathrm{p}=0.003$ ) [10]. Although some conditions were considered as research limitation (absent mechanical ventilation, positive malaria and anemia $[\mathrm{Hb}<5 \mathrm{~g} / \mathrm{dL}]$ in most subjects), inevitably these results sparked debate which underlies several studies or clinical trial to compare the efficacy of restrictive and liberal FBT.

Before determining its effect on the outcome, it is necessary to take into consideration what is the definition of "restrictive and liberal"? Is it based on the volume of each bolus, the total volume of resuscitation, the total daily volume, or the rate of delivery? This must be established in order to produce same operational definition of the study. This definition is also important to determine the factors that most influence the patient's outcome.

A pilot study in UK compared bolus volumes of $10 \mathrm{~mL} / \mathrm{kg}$ (maximum $500 \mathrm{~mL}$ per bolus) and $20 \mathrm{~mL} / \mathrm{kg}$ (maximum $1000 \mathrm{~mL}$ per bolus) in 15 minutes. The maximum volume in 4 hours was $120 \mathrm{~mL} / \mathrm{kg}$. As a result, the total volume of resuscitation in the restricted group was lower than conservative $(14.5 \%$ vs $25.7 \mathrm{~mL} / \mathrm{kg}, \mathrm{p}<0.001)$; however, there were no differences in mortality, length of PICU and hospital stay, and PICU free days in 30 days [11]. It has to be noticed that this study conducted in the developed countries with adequate facilities and low disease severity. Moreover, the total volume of conservative group resuscitation was $20.7 \mathrm{~mL} /$ $\mathrm{kg}$ in the first hour and $25.7 \mathrm{~mL} / \mathrm{kg}$ in 4 hours; much less than the FBT volume in international guidelines. Consequently, the results could not simply generalize in the daily practice.

Another study in the adult population with septic shock compared the restrictive $(\leq 60 \mathrm{~mL} /$ $\mathrm{kg}$ in 72 hours) and conservative groups (no volume limit). Similar to studies in children, 
there were differences in total fluid volume in 72 hours between the restrictive and conservative groups $(47.1 \mathrm{~mL} / \mathrm{kg}$ vs. $61.1 \mathrm{~mL} /$ $\mathrm{kg}$, respectively; $\mathrm{p}=0.01$ ); however there were no differences in mortality, incidence of organ failure, ICU and hospital length of stay, or serious adverse effects within 30 days [12]. The 72 hour fluid volume in this study was far less than the international guidelines and several previous studies, including: Rivers (168mL/kg) , [13] Process (108-130mL/kg), [14] Promise (98mL/kg), [15] or arise $(108-109 \mathrm{~mL} / \mathrm{kg})$ [16]. The total volume in 72 hours consisted of resuscitation and non-resuscitation (maintenance) fluids. This revealed that organ perfusion may still be adequate with a small volume of resuscitation, because patients still get additional maintenance fluid afterwards.

Designed to compare restrictive and liberal FBT, however those two studies were unable to solve the problem because the FBT volumes given were less than international guidelines and daily practices. In the pediatric studies, low severity illnesses might be the reason why such patients responded to the small volumes of FBT [11]. In adult studies, unblinded intervention methods and a tendency to limit the FBT volume in daily practice cause both groups got smaller volumes [12]. Therefore, it seems that so far there has not been an adequate study to determine the effect of different FBT volumes on patient outcomes.

The rate of fluid delivery also must be considered, since some study demonstrated its impact to the outcome. Two RCTs in a population of septic shock children in India, suggested rapid fluid bolus administration is associated with increased morbidity. The first RCT stated that the incidence of liver enlargement was greater in group who received $40 \mathrm{~mL} / \mathrm{kg}$ in 15 minutes than the $20 \mathrm{~mL} /$ $\mathrm{kg}$ in 20 minutes $(70 \%$ vs $35.6 \%$, respectively; $\mathrm{p}<0.01)$ [17]. The second study showed a reduced risk of mechanical ventilation and increased oxygenation index (OI) in the bolus group 15-20 minutes compared to 5-10 minutes (43\% vs 68\%; relative risk, $0.63 ; 95 \%$ CI, 0.42-0.93) [18]. Nevertheless, single-center studies and small sample size may be the limitation of both studies.

Increased morbidity and mortality after FBT are associated with impaired respiratory and neurology function. In addition, it was caused by hyperchloremic acidosis, decreased relative hemoglobin levels, and the possibility of ischemic-reperfusion injury [19-21]. Several studies have shown post-FBT hypervolemia damages endothelial glycocalyx (EGL) integrity thereby increasing vascular leakage $[22,23]$. Leakage of fluid into the interstitial space leads to edema and organ dysfunction [24]. It should also be noted that the risk of mortality increases with the severity of shock or if there are accompanying disorders, for example: respiratory and neurological disorders [21]. Therefore, it seems that the outcome of pediatric patients with septic shock is not only determined by volume or rate of fluid delivery. The severity of the disease and the amount of organ dysfunction also determine the patient's response to FBT and its outcomes.

Referring to the term "one size does not fit all", the use of FBT should consider the physiological factors of each patient. Not all patients respond well to large volumes of FBT, because there is a risk of volume overload and vascular leakage. Vice versa, patients who respond to FBT will face the risk of hypoperfusion if restricted FBT volume is given. The Starling curve has explained that stroke volume (and cardiac output) is strongly influenced by the level of myocardial contractility $[25,26]$. In case of hypotensive shock or septic cardiomyopathy, it can be predicted that patients tend to be refractory to FBT and need vasoactive drugs. Septic cardiomyopathy itself is associated with increased mortality $[27,28]$. An observational retrospective study in Dengue shock syndrome (DSS) showed a decrease of myocardial contractility in most subjects. Accordingly, the mortality in restrictive FBT group was 53\% lower than the liberal group, suggesting high amount of fluid volume may harmful in case of myocardial depression [29].

For this reason, giving FBT in a septic shock child should not merely consider the volume and rate of delivery. Measurement of myocardial contractility should be the main parameter to determine the appropriate FBT methods. Noninvasive techniques for measuring left ventricular systolic function by echocardiography or inotropy index by Doppler (USCOM) provide a lot of information about myocardial contractility under emergency conditions $[30,31]$. It is also important to measure fluid-responsiveness as a surrogate marker of FBT. Passive leg raising (PLR) and respiratory variation in aortic blood flow peak velocity are the most reliable methods in pediatric patients [32]. If myocardial contractility and fluid-responsiveness measurements become part of the protocol for managing septic shock, FBT can be adjusted to each patient's condition. Then, it will be unnecessary to debate the efficacy between restrictive and liberal FBT.

Furthermore, the same operational definition of volume and rate of delivery must be applied in the next studies. Variables that affect the outcome -such as: illness severity at presentation, time to obtain emergency management, time to get vasoactive agents, speed of antibiotic administration, availability of mechanical ventilation and hemodynamic support, daily fluid balance, and causative microorganisms- should also be analyzed in studies of pediatric septic shock. In this fashion, it provides comprehensive datas that important in developing a septic shock protocol.

\section{References}

1. Hartman ME, Zwirble WT, Angus DC, Watson RS (2013) Trends in the epidemiology of pediatric severe Sepsis. Pediatr Crit Care Med 14(7): 686-693.

2. Souza DC, Shieh HH, Barreira ER, Maria A, Ventura C, et al. (2016) Epidemiology of sepsis in children admitted to PICUs in South America. Pediatr Crit Care Med 17(8): 727-374.

3. Balamuth F, Weiss SL, Neuman MI, Scott H, Brady P, et al. (2014) Pediatric severe sepsis in U.S. children's hospitals. Pediatr Crit Care Med 15(9): 798-805.

4. Yang X, Shan C, Fan Y, Dong M (2014) An epidemiologic survey of pediatric sepsis in regional hospitals in China. Pediatr Crit Care Med 15(9): 814-820.

5. Weiss SL, Balamuth F, Hensley J, Fitzgerald JC, Bush J, et al. (2017) The epidemiology of hospital death following pediatric severe sepsis: When, why, and how children with sepsis die. Pediatr Crit Care Med 18(1): 823830 . 
6. Han YY, Carcillo JA, Dragotta MA, Bills DM, Watson RS, et al. (2003) Early reversal of pediatric-neonatal septic shock by community physicians is associated with improved outcome. Pediatrics 112(4): 793-739.

7. Davis AL, Carcillo JA, Aneja RK, Deymann AJ, Lin JC, et al. (2017) American college of critical care medicine clinical practice parameters for hemodynamic support of pediatric and neonatal septic shock Crit Care Med 45(6): 1061-1093.

8. Oliveira CF, FRN de, Oliveira DF, Gottschald AF, Moura JD, et al. (2008) Time and fluid sensitive resuscitation for hemodynamic support of children in septic shock: barriers to the implementation of the American college of critical care medicine/pediatric advanced life support guidelines in a pediatric intensive care unit in a developing world. Pediatr Emerg Care 24(12): 810-815.

9. Paul R, Melendez E, Stack A, Capraro A, Monuteaux M, et al. (2014) Improving adherence to PALS septic shock guidelines abstract. Pediatr Emerg Care 133(5): e1358-1366.

10. Maitland K, Kiguli S, Opoka R, Engoru C, Olupot O, et al. (2011) Mortality after fluid bolus in African children with severe infection. N Engl J Med 364(26): 2483-2495.

11. Inwald DP, Canter R, Woolfall K, Paul M, Zohra Z, et al. (2019) Restricted fluid bolus volume in early septic shock: results of the fluids in shock pilot trial. Arch Dis Child 104(5): 426-431.

12. Corl KA, Prodromou M, Merchant RC, Gareen I, Marks S, et al. (2019) The Restrictive IV fluid trial in severe sepsis and septic shock (RIFTS): A randomized pilot study. Crit Care Med 47(7): 951-959.

13. Rivers E, Nguyen B, Havstad S, Ressler J, Muzzin A, et al. (2001) Early goal-directed therapy in the treatment of severe sepsis and septic shock. N Engl J Med 345(19): 1368-1377.

14. Yealy DM, Kellum JA, Huang DT, Barnato AE, Weissfeld LA, et al. (2014) A randomized trial of protocol-based care for early septic shock. N Engl J Med 370(18): 1683-1693.

15. Mouncey PR, Osborn TM, Power S, Harrison DA, Sadique MZ, et al. (2015) Trial of early, goal-directed resuscitation for septic shock. N Engl J Med 372: 1301-1311.

16. Peake SL, Delaney A, Bailey M, Bellomo R, Cameron PA, et al. (2014) Goal-directed resuscitation for patients with early septic shock. N Engl J Med 371(16): 1496-506.

17. Santhanam I, Sangareddi S, Venkataraman S, Kissoon N, Thiruvengadamudayan $\mathrm{V}$, et al. (2008) A prospective randomized controlled study of two fluid regimens in the initial management of septic shock in the emergency department. Pediatr Emerg Care 24(10): 647-655.

18. Sankar J, Ismail J, Sankar MJ, Meena RS (2017) Fluid bolus over 15-20 versus 5-10 minutes each in the first hour of resuscitation in children with septic shock: A randomized controlled trial. Pediatr Crit Care Med 18(10): e435-445.

19. Levin M, Cunnington AJ, Wilson C, Nadel S, Lang HJ, et al. (2019) Effects of saline or albumin fluid bolus in resuscitation: Evidence from reanalysis of the FEAST trial. Lancet Respir Med 7(7): 581-593.

20. Myburgh J, Finfer S (2013) Causes of death after fluid bolus resuscitation: New insights from FEAST. BMC Med 11: 67-71.

21. Maitland K, George EC, Evans JA, Kiguli S, Olupot, et al. (2013) Exploring mechanisms of excess mortality with early fluid resuscitation: Insights from the FEAST trial. BMC Med 11: 68.

22. Alphonsus CS, Rodseth RN (2014) The endothelial glycocalyx: a review of the vascular barrier. Anaesthesia 69(7): 777-784.

23. Chappell D, Bruegger D, Potzel J, Matthias J, Florian B, et al. (2014) Hypervolemia increases release of atrial natriuretic peptide and shedding of the endothelial glycocalyx. Crit Care 18: 538-546.

24. Glassford NJ, Eastwood GM, Bellomo R (2014) Physiological changes after fluid bolus therapy in sepsis: A systematic review of contemporary data. Crit Care 18(6): 696.

25. Patterson SW, Starling EH (1914) On the mechanical factors which determine the output of the ventricles. J Physiol 48(5): 357-379.

26. Berlin DA, Bakker J (2015) Starling curves and central venous pressure. Crit Care 19: 55.

27. Werdan K, Oelke A, Hettwer S, Nuding S, Bubel S, et al. (2011) Septic cardiomyopathy: hemodynamic quantification, occurrence, and prognostic implications. Clin Res Cardiol 100: 661-668.

28. Raj S, Killinger JS, Gonzalez JA, Lopez L (2014) Myocardial dysfunction in pediatric septic shock. J Pediatr 164(1): 72-77.

29. Yuliarto S, Kadafi KT, Anitasari D (2019) Restrictive versus liberal fluid resuscitation in children with dengue shock syndrome: The differences in clinical outcomes and hemodynamic parameters. Int J Pediatr 7(64): 9215-9224.

30. Gaspar HA, Morhy SS (2015) The role of focused echocardiography in pediatric intensive care: A critical appraisal. Biomed Res Int 2015: 596451.

31. Madigan VM, Smith BE (2013) Non-invasive method for rapid bedside estimation of inotropy: Theory and preliminary clinical validation. $\mathrm{Br} \mathrm{J}$ Anaesth 111(4): 580-588.

32. Gan H, Cannesson M, Chandler JR, Ansermino JM (2013) Predicting fluid responsiveness in children: a systematic review. Anesth Analg 117(6): 1380-1392. 